\title{
GRAN PROPIEDAD Y MOVILIZACIÓN SOCIOPOLÍTICA DEL CAMPESINADO: LAASOCIACIÓN DE GANADEROS DEL REINO EN GALICIA DURANTE EL PRIMER TERCIO DEL SIGLO XX
}

\author{
Por \\ ANTONIO BERNÁRDEZ SOBREIRA'
}

\section{INTRODUCCIÓN}

En los últimos años ha ocupado un lugar destacado en la historiografía agraria gallega la definición del «agrarismo» como un heterogéneo movimiento social vinculado a las transformaciones socioeconómicas y políticas de la Galicia contemporánea. Desde los trabajos pioneros de X.A. Durán (1977) se ha venido insistiendo en su caracterización como complexo movemento que tenta mobilizar un grupo social (...) que ata aquela non atopara unha expresión propia dos seus intereses (CABO 1998: 11)2. Con frecuencia estas interpretaciones realizan una desnaturalización de un movimiento que presenta diversas caracterizaciones y manifestaciones ideológicas, sesgándolo en buena medida hacia una orientación pro-

\footnotetext{
${ }^{1}$ Profesor de Historia, Colexio Fingoi, Lugo.

${ }^{2}$ Optaría dicho movimiento por la resolución de una serie de metas que serían entre otras la supervivencia de la pequeña explotación familiar en el marco de la economía capitalista y la articulación política de los intereses del pequeño campesinado (CABO 1998: 11).
}

"CUADERNOS DE ESTUDIOS GALLEGOS", Tomo XLVII, Fascículo 113, Santiago 2000. 
gresista y $\backslash$ o galleguista, en definitiva alternativa al sistema, que margina a aquellos sectores que desde la defensa del orden social propugnaban también la supervivencia de la pequeña propiedad y el encuadramiento societario del campesinado ${ }^{3}$. Ello no deja de ser significativo cuando supone considerar al agrarismo gallego como una excepción dentro de un movimiento que, por lo general, se identifica en Europa y la Península Ibérica como de organización de los intereses de las clases propietarias en el contexto de su adaptación a las necesidades cambiantes de la economía global (KONING 1994, AMADO 1994) ${ }^{4}$. Es más, los estudios de carácter local aportan una visión del agrarismo imbricada en las luchas de poder entre los grupos dirigentes de la sociedad rural y con frecuencia instrumentalizadora, pero no necesariamente representante, de los intereses del pequeño campesino propietario 5 .

Obedece la consideración del agrarismo como movimiento «progresista» a una doble generalización ideológica y metodológica. Ideológica en el sentido en que se puede asumir «acríticamente» su carácter de alternativa al sistema restauracionista basándose en el mensaje transmitido a partir del discurso generado por la inteligencia agraria ${ }^{6}$. Metodológica porque se asume la expansión del asociacionismo campesino como manifestación de la consolidación del movimiento agrario y de los cambios en

\footnotetext{
${ }^{3}$ Hay que destacar en este sentido el excelente trabajo de Alberte Martínez (1989) que describe el devenir del agrarismo católico en la Galicia del primer tercio del siglo XX. Cabo (1998: 98 y ss) se inclina más por el término «sindicalismo agrícola confesional» que por «agrarismo católico». De todas formas según este autor se trataría de una desnaturalización del auténtico "agrarismo» como parte de una estrategia de los poderes establecidos (CABO 1998: 95).

${ }^{4}$ Respondería la asunción de una táctica societaria por parte de la clases propietarias a la necesidad de superar la «crisis de legitimidad» que deriva de la puesta en cuestión de los mecanismos de poder característicos del Antiguo Régimen (GARRIDO 1996: 51).

${ }^{5}$ En esta línea los trabajos de Rosende (1988), Hervés (1997), Román (1997) y Domínguez (1997) nos muestran a los grupos agrarios como relacionados con sectores terratenientes, burgueses o campesinos acomodados, con frecuencia vinculados con la emigración, y aspirantes a reemplazar la tradicional hegemonía de las clases propietarias y sustituirlos en las redes del poder local.

${ }^{6}$ Sería el caso de la interpretación sobre las actividades del grupo «Prácticas Modernas» (CABO 1997) más relacionable con los «neofisiócratas reformistas» portugueses que con las fuerzas democráticas que pugnan por la superación del sistema de la Restauración. Sobre los neofisiócratas vid. AMADO (1994: 233).
}

"CUADERNOS DE ESTUDIOS GALLEGOS", Tomo XLVII, Fascículo 113, Santiago 2000. 
la sociedad rural, sin que muchas veces encontremos elementos relativos a la eficacia real de dicho asociacionismo ni de sus relaciones con los grupos de poder tradicionales.

La necesidad de aportar una visión crítica a la que en este momento es la interpretación «oficial» del fenómeno agrarista en la Galicia del primer tercio del siglo XX se hace más evidente cuando nos encontramos con una serie de comportamientos que desde las clases dirigentes, y en la línea de lo usual en la Europa del momento, pugnaron por encuadrar al pequeño campesino-propietario lejos de cualquier tentación o veleidad revolucionaria, propugnando una reforma técnica del campo que de ningún modo cuestionaba las relaciones sociales de producción. Estos comportamientos fueron con frecuencia identificados con las organizaciones social-católicas en oposición a un agrarismo «neutro» de carácter laico y relacionado con diversas aspiraciones más o menos reformistas (HERVÉS 1991:

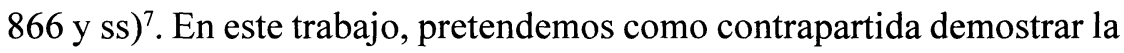
existencia de una variante del agrarismo que desde la defensa del sistema, pero no necesariamente desde la doctrina social de la Iglesia, involucró a diferentes familias políticas (católico-sociales, republicanos, liberales y conservadores de distintas familias) en el proyecto de reconducir la hegemonía social de las clases propietarias a través de la defensa de la pequeña propiedad y del cooperativismo ${ }^{8}$. LaAsociación General de Ganaderos del Reino, continuadora de la vetusta «Mesta», adquirirá en Galicia un papel dispar del adoptado en la España seca, más relacionado con la defensa de los derechos de la gran propiedad frente a la roturación de las vías pecuarias y dehesas, en la medida en que va a actuar como uno de los posibles canales de la reforma técnica de la pequeña explotación convi-

${ }^{7}$ Bajo la denominación de agrarismo neutro, ya utilizada en aquellos tiempos por sus rivales socialcatólicos, incluimos el conjunto de orientaciones agraristas no confesionales ni vinculadas con las organizaciones obreras (HERVÉS 1991: 867). Se incluirían aquí a diferentes familias políticas tales como mauristas, republicanos, liberaldemócratas, reformistas o galleguistas. Como veremos de entre sus dirigentes algunos como Pita Romero serán actores destacados en la actividad de la Asociación de Ganaderos en Galicia.

${ }^{8}$ Oscilando entre el «neofisiocratismo» revalorizador del papel de la tierra en el sistema económico y un «agrarismo tradicionalista» que opone la cultura agraria a los desmanes de la civilización industrial. Una definición para Portugal en AMADO (1994: 233-236).

"CUADERNOS DE ESTUDIOS GALLEGOS", Tomo XLVII, Fascículo 113, Santiago 2000. 
viendo con las diversas familias del agrarismo con las que con frecuencia colabora o comparte dirigentes. Mostraremos pues en primer lugar los condicionantes sociohistóricos en que se desarrolla esta organización para pasar más tarde a su descripción pormenorizada. Las fuentes para ello proceden de los fondos que de la Mesta se conservan en elArchivo Histórico Nacional, inéditos en lo referente a su vaciado y tratamiento, por lo que el trabajo aquí presentado adquiere el valor añadido de la exposición a la luz pública de una fuente de valiosas aportaciones de cara al futuro en lo referente a las relaciones de poder en el mundo rural gallego y sus vinculaciones políticas dentro del conjunto del Estado.

\section{CONTEXTO SOCIOPOLÍTICO. PROPIETARIOS Y ORGANI- ZACIONES AGRARIAS ANTE LA INTERNACIONALIZACIÓN DEL CAPITALISMO}

La elaboración de un discurso defensivo de los intereses agrarios ha sido tradicionalmente puesta de manifiesto en relación con la progresiva mundialización de la economía y la consecuente marginación de los intereses de las clases propietarias frente al nuevo discurso industrialista dominante desde las últimas décadas del siglo XIX (TRACY 1989). En economías de débil industrialización, como es el caso de la española, se elaboraría además junto al discurso de las elites agrarias una alternativa ideológica populista que combina los intereses de sectores de la pequeña burguesía con la resistencia del campesinado al pacto oligárquico entre la burguesía y las clases propietarias, uniéndose por otro lado a las diferentes fuerzas (socialismo, anarquismo...) que pugnan por la movilización social como instrumento de transformación del sistema dominante (ALONSO 1990: 82 y ss) ${ }^{9}$.

${ }^{9}$ La figura del movimiento antiforal, con dirigentes populistas como el mítico Basilio Álvarez, se ajustaría a este modelo tal y como se señala en CABO (1998: 76y ss). Estos political midlemen, procedentes en buena parte de las clases medias urbanas hegemonizan la acción colectiva de un campesinado parcelario al que utilizan como masa de maniobra electoral para romper el monopolio político de la vieja élite turnista (SOUTELO 1996: 87).

"CUADERNOS DE ESTUDIOS GALLEGOS", Tomo XLVII, Fascículo 113, Santiago 2000. 
Es en este contexto de movilización de los diferentes sectores sociales involucrados en la cuestión agraria en el que surge el interés de las clases dominantes por apelar a estrategias reformistas que frenen la problemática generada por la cuestión obrera y el éxodo rural (KONING 1994: 192). La organización de la patronal agraria es pues una respuesta defensiva ante las transformaciones socioeconómicas, presentando además caracteres inequívocos como el corporativismo, el proteccionismo y la desconfianza ante el libre mercado ${ }^{10}$. El estudio pues de dichas organizaciones aporta elementos de juicio para la comprensión de una serie de elementos relacionados con la transformación de la sociedad rural en el contexto de su integración en una economía capitalista mundializada.

- Comprensión de los cambios en las relaciones siempre ambivalentes (entre la conflictividad y la dependencia mútua) entre el pequeño campesino propietario o no y las clases dirigentes (WOLF 1971, HOBSBAWM 1976, HUIZER 1982).

- Comprensión de la capacidad de resistencia o continuidad del Antiguo Régimen (o por lo menos de parte de sus grupos dirigentes) en adaptación a unas estructuras socioeconómicas cambiantes (MAYER 1984).

- Comprensión de la capacidad de elaboración de un discurso ruralista que busca la consolidación de la pequeña propiedad como rompeolas frente a la conflictividad social derivada de la consolidación del capitalismo (KONING 1994).

En el caso concreto de la España de la Restauración, sobre todo en su momento de crisis entre 1914 y 1923, el asociacionismo patronal agrario viene relacionándose con la defensa de la propiedad y la producción agrarias en forma de un entramado corporativo que aglutinó a asociaciones tradicionales (Asociación de Ganaderos, Sociedades Económicas) con otras

\footnotetext{
${ }^{10} \mathrm{La}$ constitución en la segunda mitad del siglo XIX de organizaciones como el Bund der Landwirte alemán o la Société des Agriculteurs de France tiene su paralelo en España en la consolidación de la Asociación General de Ganaderos del Reino como una institución semioficial que busca aglutinar a grandes y pequeños propietarios en la «modernización controlada» del sector, así como en la constitución de las Cámaras Agrarias o de la Asociación de Agricultores de España.
}

"CUADERNOS DE ESTUDIOS GALLEGOS", Tomo XLVII, Fascículo 113, Santiago 2000. 
de nuevo cuño (Cámaras Agrícolas, Federaciones y Sindicatos Agrarios) (REY 1992: 48, FLORENCIO 1994: 83) ${ }^{11}$. Han sido los estudios adaptados a las diferentes realidades geográficas dentro del Estado los que han aportado elementos más enriquecedores para la comprensión de la instrumentalización del societarismo por las clases propietarias. Por ejemplo son ya clásicas las aportaciones de los países de lengua catalana, tanto Catalunya (MAYAYO 1995) como el País Valencià (GARRIDO 1996), en los que se insiste en la conciencia de la necesidad de una reforma controlada del sector agrario que no cuestione las relaciones sociales de producción. Los grupos propietarios se adaptarían a las transformaciones en las vías de participación política para hegemonizar a las clases subordinadas a través de un entramado societario de nuevo cuño (MILLÁN 1997) ${ }^{12}$. La organización societaria de la patronal agraria sería un fenómeno general en el Estado Español relacionado con la articulación sociopolítica de la oligarquía agraria tradicional (SEVILLA 1979: 87) y la subordinación del pequeño campesinado (CASTILLO 1976: 36), en un movimiento de alianza de los intereses de los grandes y pequeños propietarios (ARRIBAS 1989: 47). Esta «alianza de clase» adquiriría en concreto en las economías de pequeña explotación un papel determinante en los procesos de transformación del sector agrario vía «modernización» técnica inducida a través del apoyo estatal y del capital (MAJUELO 1991, PUENTE 1992, LANGREO 1995). Las asociaciones patronales se constituirían pues en instrumentos de defensa frente a un sistema económico, el capitalismo industrialista, que resultaba lesivo para los intereses de la gran propiedad en la defensa de un desarrollo industrial frente a los poderes agrarios tradicionales, y que presionaba fundamentalmente a través de la fiscalidad y

\footnotetext{
"Contrasta la caracterización que se hace del movimiento agrario en sus múltiples facetas como reaccionario, en trabajos como el citado de Rey o el de Mercedes Cabrera (1983), con la visión desarrollada por la historiografía gallega del Agrarismo. La coexistencia en Galicia de este movimiento agrario, representante de las elites tradicionales, con el societarismo campesino antiforista y anticaciquil hace necesaria la caracterización y diferenciación interna de unos movimientos que en ocasiones podían compartir prácticas y planteamientos.

${ }^{12}$ Se llega incluso a generar una legislación de orientación reformista tal como la Ley de Sindicatos Agrícolas de 1906 que desde el poder interesa no desarrollar en todas sus consecuencias, alentando y al mismo tiempo obstruyendo la reforma del sistema (GARRIDO 1994).
}

"CUADERNOS DE ESTUDIOS GALlEGOS", Tomo XLVII, Fascículo 113, Santiago 2000. 
la competencia a la pequeña. Ello no evita la contradicción de que los promotores de dicha movilización fuesen al mismo tiempo personas comprometidas con los partidos turnantes y por lo tanto interesadas en la estabilidad del sistema político (ELORZA 1986: 32, GARRIDO 1994).

\section{LAASOCIACIÓN DE GANADEROS DELREINO: CUESTIONES PREVIAS}

Ya ha sido mencionada la relación de laAGGR con el «Honrado Concejo de la Mesta», tal y como se señalaba en un folleto de 1849 referente a la disolución de esta institución característica del Antiguo Régimen ${ }^{13}$. En esta línea se continuaba con una serie de labores relativas a la conservación de las Cañadas Reales y servidumbres públicas, adaptándose lógicamente a las consecuencias derivadas de la liquidación del entramado «feudal». La transformación de las estructuras socioeconómicas mediante la construcción del Estado Liberal implicó por otro lado el compromiso de la Corporación con el fomento de la ganadería nacional y defensa de los intereses pecuarios en todos sus aspectos ${ }^{14}$. Aquí se puede observar una clara declaración de intenciones en torno a dos aspectos: la opción por las medidas de mejora técnica del sector y la defensa corporativa de los intereses sociales en torno al mismo. El corporativismo complica además las actuaciones de una Asociación que goza de una doble personalidad jurídica, como delegada del Gobierno y representante de la Clase Ganadera $^{15}$. En cuanto a los asociados, se incluía la posibilidad de los socios colectivos, lo cual a priori debería constituir un estímulo para las asociaciones de pequeños o medianos propietarios que pueden así disfru-

\footnotetext{
${ }^{13}$ Por Real orden de 31 de Enero de 1836 se mandó que aquella corporación se denominase Asociación general de Ganaderos, vid. F. Hilarión Bravo (1849): Noticia sucinta del origen, organización y atribuciones de la Asociación General de Ganaderos, Madrid, p. 7.

${ }^{14}$ Vid. AGGR (1924): Reglamento de la Asociación General de Ganaderos del Reino, Madrid: Imprenta M. Tutor, art. $2^{\circ}$, p. 4.

${ }^{15}$ Así se refleja en el artículo tres del citado Reglamento, p. 4. Para agilizar sus actividades y gozar del máximo número de ventajas se adaptó a la Ley de Sindicatos de 1906 según R.O. de 21 de Julio de 1914.
}

"CUADERNOS DE ESTUDIOS GALLEGOS", Tomo XLVII, Fascículo 113, Santiago 2000. 


\section{Cuadro I: Síntesis órganos de poder AGGR}

\begin{tabular}{ll}
\hline Órgano & Función \\
\hline \multirow{3}{*}{ Junta General } & Supervisión actividad \\
& Control cuentas \\
& Votación Presidencia \\
Comisión Permanente & Dirección y Administración \\
& Organización-control Fomento \\
& Aprobación Reglamentos filiales \\
Secretaría General & Gerencia \\
& Correspondencia \\
& Pagos \\
\hline
\end{tabular}

Fuente: AGGR (1924): Reglamento de la $A G G R$, Madrid.

tar de los beneficios de laAsociación previo pago de una cuota comunitaria. Y dichos beneficios eran interesantes pues incluían la adquisición de inputs, acceso a innovaciones biológicas o técnicas, seguros, ventas cooperativas, etc. En contraposición, la rígida jerarquización interna de la Asociación y el peso de los grandes propietarios de la España seca en sus estructuras de poder, dejaban en clara desventaja los posibles intereses del pequeño campesinado ${ }^{16}$.

Buena parte del poder dentro de la Asociación recaía en el Secretario General, que ejercía una gran influencia a través del control sobre los créditos y la correspondencia. Además, el control de la Comisión Permanente sobre los concursos y las diferentes actividades de fomento, junto con la aprobación de los reglamentos, dotaba a la organización de un centralismo que evitaba cualquier atisbo de autonomía o federalismo dentro

${ }^{16}$ Así lo denunciaba el publicista agrario, y furibundo crítico de los herederos de la Mesta, Bartolomé Calderón en un artículo de 1904 sobre los intentos de la AGGR por gestionar el abastecimiento de carne de las grandes poblaciones, vid. B. Calderón (1904): «Un peligro para la Riqueza pecuaria del Norte de España», Prácticas Modernas, n48, p. 281.

"CUADERNOS DE ESTUdIOS GALLEGOS", Tomo XLVII, Fascículo 113, Santiago 2000. 
Cuadro II: organigrama AGGR

\begin{tabular}{ll}
\hline Entidad & Función-ámbito actuación \\
\hline Comisión Permanente & Directiva \\
Comisiones & Cooperativa \\
& Concursos-divulgación \\
& Crédito \\
& Sanidad-industrias derivadas \\
& Cañadas \\
& Aranceles \\
Secciones & Fomento diferentes especies \\
Filiales & Regionales-provinciales \\
& Locales \\
Visitadores & Representación provincial \\
\hline
\end{tabular}

Fuente: AGGR (1924): Reglamento de la $A G G R$, Madrid.

de una Asociación que se dotaba de numerosas filiales de carácter local o provincial (REY 1992: 71). Además, la propia adscripción de clase de sus dirigentes, relacionados con los grandes títulos nobiliarios, implicó junto con la rigidez organizativa la escasa proyección entre los pequeños propietarios con los que obtendrá más éxito el catolicismo social (REY 1992: $72)^{17}$. Estas limitaciones comprometían las posibilidades que encerraba la AGGR para el desarrollo de la cooperación agrícola como vía de «modernización» del sector pecuario, aunque son encuadrables entre otras iniciativas de la Europa del momento en las que los notables y terratenientes

${ }^{17}$ Es significativo el siguiente texto de Elorza (1986:32) referente a las contradicciones internas de la AGGR y la Asociación de Agricultores de España: Hay que advertir que los elementos dirigentes de ambas organizaciones se encontraban muy comprometidos con los partidos políticos turnantes. Ejemplo de tal compromiso eran, por citar los casos más llamativos, el Vizconde de Eza, Jesús Cánovas del Castillo, Mariano Matesanz, el Marqués de la Frontera o el Marqués de Alonso Martínez (...) sin embargo en sus bases se apreciaba el surgimiento de un radicalismo de signo agrarista que entraba en contradicción con los programas sostenidos por los líderes patronales.

"CUADERNOS DE ESTUDIOS GALLEGOS", Tomo XLVII, Fascículo 113, Santiago 2000. 
asumen la creación de una red societaria como vía de consolidación de sus intereses, hecho que ya ha sido señalado con anterioridad (CLEARY 1989: 34$)^{18}$. Todo ello no deja de ser una muestra de un proceso más amplio y complejo de reelaboración de las decisiones políticas y económicas caracterizado por la patrimonialización de las estructuras del Estado y la adaptación de las tradicionales clientelas políticas a los nuevos mecanismos participativos (BERNÁRDEZ 1998: 11) ${ }^{19}$.

\section{CONSTITUCIÓN DE FILIALES DE LA AGGR EN GALICIA (1918-1936)}

En el contexto de la crisis aguda del período 1917-1919, y coincidiendo en el tiempo con la ofensiva societaria socialcatólica (MARTíNEZ 1989: 69), se produce la constitución de filiales de laAsociación de Ganaderos en Galicia. Ello obedece sin duda a la necesidad de una alternativa técnica a la movilización social del momento así como al intento de hegemonización de las redes de exportación del excedente pecuario gallego a los centros urbanos del Estado ${ }^{20}$. La primera en constituirse es la Junta Provincial de Lugo (30-VIII-1918) vinculada a los poderes instalados en la Diputación

${ }^{18}$ Esta potencialidad de las organizaciones corporativas para el «desarrollo económico» del sector agrario era especialmente anunciada desde el social-catolicismo, para muestra J. Elías de Molins (1912): La Asociación y Cooperación Agrícolas. Estudio Social-Agrario, Barcelona: Imprenta Barcelonesa. En el caso francés es paradigmática la competencia entre católicos y republicanos por la captación del campesinado en defensa de sus intereses políticos (CLEARY 1989: 33 y ss.).

${ }^{19} \mathrm{La}$ construcción de un entramado societario, dentro de una concepción corporativa de la sociedad, se convierte en instrumento de la hegemonía de clase en una estructura social donde los nuevos mecanismos participativos pueden poner en cuestión las tradicionales tácticas políticas clientelares, sobre todo ante el nacimiento de las organizaciones de clase y democráticas. Vid. sobre la cuestión REY (1992: 31 y ss.).

${ }^{20}$ La cuestión de la alternativa técnica a la movilización social se vió reflejada en las Asambleas Agrarias de los años precedentes en el tenso debate entre los sectores «técnico» y «populista» del Agrarismo (CABO 1998: 84 y ss). En este sentido, observaremos en la constitución de las Juntas de Ganaderos el papel protagonista de dirigentes de la vertiente técnica como Rof Codina o García Ibarra.

"CUADERNOS DE ESTUDIOS GALLEGOS", Tomo XLVII, Fascículo 113, Santiago 2000. 
Provincia ${ }^{21}$. Aún así mostraba una heterogeneidad ideológica interna representativa de las diferentes familias políticas en pugna por el control social del campo ${ }^{22}$. Heterogeneidad que a priori no supone un problema dada la vertiente eminentemente técnico-económica de las Juntas, aunque las disparidades derivarán con frecuencia en dificultades organizativas.

Cuadro III: Directivos Junta Provincial Lugo 1918

\begin{tabular}{ll}
\hline Cargo & Nombre \\
\hline Presidente & José Benito Pardo \\
Vicepresidente & Ángel López Pérez \\
Secretario & José García Armendáritz \\
Vocal natolvisitador & Luís Quiroga Espí \\
Vocales & Francisco García Arnero \\
& Constantino Grandío Teás \\
& Manuel Yáñez Rodríguez \\
& Manuel Pardo Becerra \\
& Purificación de Cora \\
& José de la Barrera Montenegro \\
\hline
\end{tabular}

Fuente: AHN, Fondo Mesta, Leg. $925 \backslash 2$

Se observa dentro de la directiva la presencia de elementos clave de la vida política provincial como los Pardo $^{23}$ o los Quiroga ${ }^{24}$, políticos locales como el alcalde de Lugo, López Pérez, propietarios y técnicos. Esta línea se aprecia con más claridad en la Junta de A Coruña (10-X-1918) donde

${ }^{21}$ Así se lo comunicaba el Inspector Veterinario García Armendáritz al secretario de la AGGR, Marqués de la Frontera, cuando proponía como presidente de la Junta a José Benito Pardo, presidente de la Diputación cuya influencia es decisiva en toda la provincia, AHN: Fondo Mesta, Leg. 925 2.

${ }^{22}$ En esta lista figuran mauristas, conservadores, integristas, liberales, demócratas y hasta un casi republicano, "Carta de SánchezAnido al Marqués de la Frontera», agosto 1918, AHN: Fondo Mesta, Leg. 925 2.

${ }^{23}$ Una explicación elaborada sobre el acceso de la familia Pardo al poder provincial y de sus bases de poder territorial en la Terra Chá se puede encontrar en CARDESÍN (1992: 292 y ss.).

${ }^{24}$ Sobre Luís Quiroga decía García Armendáritz en 1918: ...es hermano de D. Joaquín Quiroga Espí, diputado siempre por esta capital, AHN: Fondo Mesta, Leg. 925 2.

"CUADERNOS DE ESTUDIOS GALLEGOS", Tomo XLVII, Fascículo 113, Santiago 2000. 
aparecen elementos característicos del agrarismo técnico del momento junto con próceres locales y provinciales. Así, lo más llamativo es la abundante presencia de técnicos vinculados con los inicios del agrarismo gallego a través de Prácticas Modernas. Es el caso de los Hernansáez, Rof, Hernández Robredo o del arbitrista y publicista agrario García Ibarra. Junto a ellos, representantes de la gran propiedad y la política tradicional como Romero Donallo o el Vizconde de San Alberto así como notables del poder local como el ortegano Federico Maciñeira. Estas relaciones entre el poder político y territorial y los reformistas en un proyecto de mejora técnica del agro ${ }^{25}$ derivaron en una conflictividad que se hace evidente en las dimisiones de Rof y García Ibarra (octubre 1919) y en los problemas para asegurar el normal funcionamiento de la Junta en 1923 ante la defunción de Romero Donallo y el traslado de residencia de Hernansáe ${ }^{26}$.

De todas formas en los últimos años 20 se consolida el poder de los técnicos dentro de la Junta dado el importante peso que va a adquirir Fortunato García Ibarra y la sucesivas crisis y cambios de dirigentes hasta que en 1930 asuma la presidencia el líder ortegano Pita Romero, en lo que supone el triunfo del sector más vinculado al agrarismo burgués y «progresista» frente a los políticos tradicionales ${ }^{27}$. Serán las dos Juntas pione-

${ }^{25}$....mejora y fomento de la ganadería, procurando al efecto la organización de concursos, certámenes y conferencias, establecimiento de paradas, formación de registros genealógicos y de la Estadística Pecuaria (art. $3^{\circ}$ «Reglamento de la Junta Provincial», AHN: Fondo Mesta, Leg. 922 2).

${ }^{26}$ En marzo de 1924 asumen la presidencia el Vizconde de San Alberto y la vicepresidencia el Conde de Canillas, en abierta conflictividad con el sector técnico que apostaba por las figuras de Rioja (Agrónomo) y Rof (Veterinario) ante la exagerada susceptibilidad de Canillas, AHN: Fondo Mesta, Leg. 922\2. La opción de la Comisión Permanente por el desempeño de los cargos de importancia por personas que por su industria y propiedad tengan relación con la industria pecuaria y sin que figuren en tales cargos funcionarios del Estado abortó estos movimientos de los técnicos.

${ }^{27}$ En la Directiva de 1928 se podía encontrar a técnicos como Pascual Jiménez, Rof, Sanz de Andino o Escauriaza, representantes de la burguesía comercial y financiera como Barrié, y elementos protagonistas del arbitrismo agrario como Pita o García Ibarra. La presencia de la alta burguesía urbana no debe resultar chocante, así por ejemplo durante la II República adquirirá un papel protagonista en la Junta de Pontevedra el industrial Javier Sensat Curbera de Alcabre (Vigo), que asímismo venía siendo presentado como un ejemplo de propietario modelo dada la posesión de una explotación lechera innovadora en las afueras de la metrópoli olívica (La Industria Pecuaria, 20-XI-1928, 10-I-1929 y 20-I-1929; AHN: Fondo Mesta, Leg.926).

"CUADERNOS DE ESTUDIOS GALLEGOS", Tomo XLVII, Fascículo 113, Santiago 2000. 
Cuadro IV: Directivos Junta Provincial Coruña 1918

\begin{tabular}{ll}
\hline Cargo & Nombre \\
\hline Presidente & Felipe Romero Donallo \\
Vicepresidente & J.M. Hernansáez \\
Secretario & José Aranguren \\
Tesorero & Nicasio Alba \\
& A. Fraile \\
& L. Hernández Robredo \\
& J. Rof Codina \\
& R. Marín \\
& J. Asunsolo \\
& R. LLamas \\
A. Viñes \\
F. López Riobóo \\
A. García \\
F. Maciñeira \\
Vizconde San Alberto \\
R. Molina \\
J. Longueira \\
A. Fernández \\
Fortunato García Ibarra \\
L. Mayor \\
\\
\end{tabular}

Fuente: AHN, Fondo Mesta, Leg. $922 \backslash 2$.

ras las que en los años de la República intenten la creación de una Junta Regional que asuma un protagonismo semejante por ejemplo al de los ganaderos catalanes ${ }^{28}$.

En el sur de Galicia, área más vinculada con las movilizaciones antiforistas $^{29}$, la constitución de la Juntas provinciales es más tardía. En 1919

${ }^{28}$ Los dirigentes principales de esta Junta serían Pita Romero y José Benito Pardo, en el contexto de la movilización de los intereses agrarios en el bienio progresista, vid. «Carta de la Asociación General a la Junta de Coruña, 1-X-1932», AHN: Fondo Mesta, Leg. $922 \backslash 2$.

${ }^{29}$ Vid. al respecto la completa síntesis elaborada por CABO (1998: 116-127) referente al antiforismo de la Galicia meridional, en contraste con la vertiente más económica del norte.

"CUADERNOS DE ESTUDIOS GALLEGOS", Tomo XLVII, Fascículo 113, Santiago 2000. 
hay un intento de constitución de una Junta Local en Vigo en la que junto a próceres locales aparece la figura del filocarlista Amador Montenegro Saavedra, vinculado al grupo Prácticas Modernas ${ }^{30}$, pero no será hasta el período primorriverista, y dentro de la estrategia por consolidar los apoyos al Régimen en el campo, cuando se constituyan las Juntas Provinciales de Ourense (8-XI-1926) y Pontevedra (29-XI-1926) ambas directamente vinculadas a sus respectivas Diputaciones, con las que comparten presidentes $^{31}$. Esta dependencia de la administración le confiere a las Juntas un carácter irregular, con sucesivos altibajos y problemas que suponen una escasa presencia social ${ }^{32}$. Hay que entender la confluencia de las actuaciones del funcionariado y los poderes locales dentro de la estrategia de establecimiento de «fórmulas de encuadramiento organizativo oficial» (como las Cámaras Agrícolas), que son instrumento de la organización corporativa en defensa de los intereses de las clases dominantes (REY 1992: 199 y ss.).

Precisamente este factor supone una coincidencia con las intenciones de las organizaciones católico-sociales, también apoyadas en los técnicos y notables locales ${ }^{33}$. En la Junta coruñesa, por ejemplo, serán muy significativas las fricciones entre Ganaderos y Católicos por el control de los concursos pecuarios y del entramado cooperativo. Así, en 1930 Pascual

${ }^{30}$ «Expediente relativo a nombramiento de Presidente de la Junta Local de Ganaderos, Vigo, 25-I-1919», AHN: Fondo Mesta, Leg. 1483.

${ }^{31}$ Nuevamente es decisiva la combinación de técnicos y poder provincial. En el caso ourensano, el presidente de la Diputación, General de Brigada D. Celso Casar Blanco, se apoyará en la labor del Inspector de Higiene Pecuaria Javier Prado así como en el Agrónomo Vicente Ribadeneira. En Pontevedra Daniel de la Sota contará con los técnicos García Buela, Gómez Bargo y Cambronero. Vid. AHN: Fondo Mesta, legs. $925 \backslash 2$ y 926.

${ }^{32}$ En 1932 le decía el Marqués de la Frontera a De la Sota: ...hace un siglo que no le he visto ni sé nada de Ud, no habiendo logrado tampoco contestación a ninguna de las cartas, oficios ni invitaciones que se han dirigido a Vd por la Asociación para la Junta de Pontevedra, que realmente no tiene existencia... ("Carta del Marqués de la Frontera a Daniel de la Sota, 6-V-1932», AHN: Fondo Mesta, Leg. 926). La ausencia de actividades respondía ni más ni menos a la marginación de De la Sota ante su compromiso político con la Dictadura de Primo.

${ }^{33}$ Martínez López reafirma esta tesis al describir un anticaciquismo católico que lo es sólo en teoría al no cuestionar las bases del sistema, aunque los enfrentamientos entre los notables locales o «caciques malos» con los párrocos sean frecuentes en el ámbito parroquial (MARTÍNEZ 1989: 239-243).

"CUADERNOS DE ESTUDIOS GALLEGOS", Tomo XLVII, Fascículo 113, Santiago 2000. 
Jiménez escribía al Marqués de la Frontera refiriéndose a los roces entre la Junta y sectores católicos de la Federación Provincial ${ }^{34}$. Antes, en 1921 llegó a plantearse el ingreso de la Junta de Coruña en la Federación Católica Agraria ${ }^{35}$ y elementos socialcatólicos fundaron Juntas Locales que buscaban una línea autónoma con respecto a la Provincial ${ }^{36}$. Las diferencias de criterios en asuntos como los mataderos cooperativos de Porriño motivaron por añadidura conflictos entre dos posturas que en buena medida buscaban el mismo objetivo hegemónico.

«...una de las cosas hechas más contra la opinión de las personas conocedoras de los asuntos de la ganadería fué el matadero de Porriño. En efecto, se anticipó que no respondía ni a un estado definitorio de cooperación ni a una necesidad de la ganadería nacional ni a una satisfacción de los intereses generales, y especialmente del consumidor, ni a nada que no fuese producir un efecto, no sabemos con qué fines, pero desde luego torpemente visto, puesto que el fracaso era seguro» ${ }^{37}$.

\section{ACTUACIONES DE LA AGGR EN GALICIA}

Hemos insistido en las páginas anteriores en el papel de la Asociación de Ganaderos dentro de un estrategia de reforma controlada del sistema para la consolidación de la pequeña propiedad al servicio de los intereses de la grande. Ello motiva una serie de actuaciones concretas que aquí

\footnotetext{
${ }^{34}$ La explicación era compleja ya que se mezclaban la animadversión entre Pita y los católicos (dados los conflictos con la Federación Agraria de Ortigueira), las disensiones internas en la Junta y los vínculos con las redes caciquiles, vid. AHN: Fondo Mesta, Leg. $922 \backslash 2$.

35 «Carta de Hernansáez al Marqués de la Frontera, 9-III-1921», AHN: Fondo Mesta, Leg. $922 \backslash 2$.

${ }^{36}$ Nos referimos en concreto a la Junta de Santiago (6-VII-1927) que buscaba una proyección comarcal en los concellos de Santiago, Trazo, Teo y Vedra, y era presidida por el notable católico Jacobo Varela de Limia (AHN: Fondo Mesta, Leg. 1483).

${ }^{37}$ El texto procede del órgano oficial de la Asociación, La Industria Pecuaria, 10 III-1930.
}

"CUADERNOS DE ESTUDIOS GALLEGOS", Tomo XLVII, Fascículo 113, Santiago 2000. 
sintetizaremos en tres grandes grupos: la construcción de un entramado societario, el desarrollo de actividades de difusión de innovaciones y la participación en las redes mercantiles en torno al sector pecuario.

Desde un primer instante, la Asociación buscará apoyar su implantación en el cada vez más numeroso entramado societario campesino. Para muestra, la relación de socios colectivos de la Junta de A Coruña en 1919, que suponían un total de 789 socios individuales (cuadro V). En el caso de Lugo, se citaban en 19191062 socios pertenecientes a diversas asociaciones de la provincia ${ }^{38}$. Las sociedades afiliadas muestran el interés por instrumentalizar la red de sociedades de seguros mútuos, heredera de las tradicionales «obrigas», para emplearlas en la difusión de los fines de la Asociación en cuanto a innovación técnica y participación cooperativa. Sin embargo, la relación de asociados de Coruña para el año 1929 parece sugerir un cierto fracaso en la pugna por hegemonizar el societarismo campesino, ya que nos encontramos sólamente con 36 socios entre individuales y colectivos ${ }^{39}$.

En el caso lucense, a fines de los años veinte y en la época republicana se opta por la constitución de numerosas Juntas Locales estrechamente relacionadas con las redes del poder municipal ${ }^{40}$.

${ }^{38}$ AHN: Fondo Mesta, Leg. 925 2. A principios de los años 20 Lugo sería la Junta más populosa con 1812 afiliados, por encima de filiales tan influyentes como Santander (963), Zaragoza (688) o Valladolid (330). Ello es demostrativo del peso de los pequeños y medianos propietarios frente a los terratenientes de la España seca (REY 1992: 72).

${ }^{39} \mathrm{De}$ esos 36, 30 eran individuales, procedentes en buena medida de zonas urbanas o periurbanas (10 de A Coruña, 8 de Santiago, 3 de Ortigueira y 2 de Ferrol). Los socios colectivos eran las Cámaras agrícolas de Santiago y A Coruña, la Federación Agraria de Ortigueira, la Junta Comarcal de Bergantiños y dos sociedades de seguros del área de Ortigueira, lo cual suponía un aporte numérico significativo pero muy localizado.

${ }^{40}$ La Junta de Xove-Lago por ejemplo (1935) corresponde a la iniciativa de un exportador de maderas local interesado en la comercialización de bueyes y terneras. Entre los objetivos de la de Meira, estaban el control de los usos colectivos, guardería rural, defensa de los intereses ganaderos... vid. AHN: Fondo Mesta, Leg. 1483. Obedecía esta táctica a la necesidad de fomentar los socios colectivos ante el predominio de los pequeños ganaderos en la provincia, tal y como se discutió en la Comisión Permanente en abril de 1932, AHN: Fondo Mesta, Leg. 1483.

"CUADERNOS DE ESTUDIOS GALLEGOS", Tomo XLVII, Fascículo 113, Santiago 2000. 
Cuadro V: relación socios colectivos Junta Coruña 1919

Sociedad de Ganaderos de Coristanco
Sociedad de Seguros Mútuos de San Claudio
Cámara Agrícola Santiago
Cámara Agrícola Coruña
Sociedad de Seguros Mútuos de Santiago de Mera
Sociedad Mútua Ganadera de San Xulián de Senra
Sociedad Ganadera de Cerdido
Sociedad Ganadera «El Sor»
Sindicato Agrícola de Agualada
Sociedad de Seguros Mútuos de Vilarrube
Sociedad Ganadera Couzadoiro
Sociedad «La Prosperidad» de Esteiro
Sociedad «La Legalidad» de Regoa
Sociedad «del Yermo»

Fuente: AHN, Fondo Mesta, Leg. $922 \backslash 2$

Cuadro VI: Juntas Locales Lugo 1929-1936

\begin{tabular}{ll}
\hline Meira (1928) \\
Becerreá (1929) \\
Neira de Xusá (1929) \\
Paradela (1929) \\
Piedrafita do Cebreiro (1929) \\
Poboa de San Xulián (1929) \\
Xove (1935) \\
\hline
\end{tabular}

Fuente: AHN, Fondo Mesta, Leg. 1483.

"CUADERNOS DE ESTUDIOS GALLEGOS", Tomo XLVII, Fascículo 113, Santiago 2000. 
Cuadro VII: Concursos subvencionados AGGR en Galicia 1912-30

\begin{tabular}{ll}
\hline Fecha & Número \\
\hline 1912 & 18 \\
1915 & $6^{*}$ \\
1921 & $9^{* *}$ \\
1923 & 8 \\
1924 & 13 \\
1925 & 5 \\
1926 & 5 \\
1927 & 9 \\
1928 & 12 \\
1929 & 8 \\
1930 & 5 \\
\hline
\end{tabular}

Fuente: La Industria Pecuaria (1-XII-1915; 10-XII-1921); AGGR (1925): Concursos de ganados organizados y subvencionados por la Asociación General de Ganaderos durante el ejercicio 1924-25, Madrid: Tip. Huelves y cia; AHN: Fondo Mesta, Legs. 774 y 780.

* Se toman aquí sólo los de Lugo y Coruña (La Industria Pecuaria, 1-XII-1915);

** Datos Coruña, Memoria Actividades Junta Provincial, y Ponteareas (La Industria pecuaria, 10-XII-1921).

La dificultad por desarrollar un entramado societario subordinado no abortó lo que se puede considerar el mayor éxito de la AGGR, su participación en los proyectos de innovación inducida en el sector pecuario ${ }^{41}$. En este sentido, el carácter semioficial de la Asociación, encargada de canalizar las subvenciones públicas para la difusión de innovaciones a través de los concursos y exposiciones, acercó necesariamente a aquellos cuyas opciones políticas podían discrepar de la línea de la AGGR (como el propio Rof Codina $)^{42}$.

${ }^{41}$ Entre las funciones de la Asociación ocupa un lugar destacado organizar y subvencionar concursos y exposiciones de ganados y procurar que sean de utilidad para el fomento pecuario, vid. AGGR (1924): Reglamento de la Asociación General de Ganaderos del Reino, Madrid: Imp. M. Tutor, art. $5^{\circ}$, p.6. La AGGR se instituiría como uno de esos «primeros adoptantes» que ejercen de intermediarios como líderes de opinión en la difusión de innovaciones entre los innovadores y el entramado social (GARCÍA 1977: 35).

${ }^{42}$ Es perfectamente aplicable aquí el aserto de Cabo (1997: 7) acerca de las relaciones del grupo Prácticas Modernas con laAdministración: ...Isto non obsta para que apoien con entusiasmo toda iniciativa de fomento técnico proveniente da Administración, como por exemplo as subvencións ós concursos de gando, a creación de centros agronómicos, o establecemento de paradas de sementais oficiais con reproductores seleccionados...

"CUADERNOS DE ESTUDIOS GALLEGOS", Tomo XLVII, Fascículo 113, Santiago 2000. 
La difusión de innovaciones en el sector agrario a través del estímulo del premio o del prestigio ante la comunidad local es una práctica adoptada en el siglo XIX de las agriculturas europeas y convertida en el siglo $\mathrm{XX}$ en uno de los motores del proceso de «mejora» de la cabaña ganadera (FERNÁNDEZ 1992: 271 y ss, VEIGA 1997) ${ }^{43}$. La muestra aportada en el cuadro VII permite observar la relativa continuidad con que la AGGR acometió la subvención de este tipo de actuaciones en Galicia, concentrándolas en una serie de actos comarcales que justifican su escaso núme$\mathrm{ro}^{44}$. Parece de todas formas que las posibilidades de organización de dichos eventos pasaban por la capacidad ecónomica y política de los poderes involucrados. En esta línea, la Diputación de Lugo asumió desde comienzos de siglo un protagonismo institucional que se echaba en falta en las demás Diputaciones gallegas ${ }^{45}$. Otro aspecto a tener en cuenta era la disponibilidad de dichos poderes a la hora de colaborar con sus medios en las actividades innovadoras. Por ejemplo desde La Industria Pecuaria se denunciaba en 1914 la negativa del Ayuntamiento de Lugo a subvencionar el concurso de ganados ${ }^{46}$. Entre la disponibilidad de los poderes locales entraba por supuesto la capacidad para movilizar las redes de cliente-

${ }^{43} \mathrm{La}$ importancia de los concursos en la introducción de innovaciones fue reseñada por Rof Codina a lo largo de toda su obra. Como muestra, su completa síntesis en ROF (1953): La raza bovina gallega rubia mejorada, Lugo: Artes Gráficas Gerardo Castro.

${ }^{44}$ Número que es inferior a las actuaciones en otras provincias del norte como Guipúzcoa donde en 1924-25 se subvencionaron 8 concursos y 8 «concursillos» de toros sementales, pero semejante a los números de Asturias o Vizcaya, vid. AGGR (1925): Concursos de ganados organizados y subvencionados por la Asociación General de Ganaderos durante el ejercicio 1924-25, Madrid: Tip. Huelves y cia.

${ }^{45}$ Así lo resaltaba Rof en 1915 al comentar su política de estímulo a la innovación agropecuaria mediante el premio en forma de maquinaria agrícola, sistema para el veterinario contraproducente ya que el labrador gallego no encuentra estímulo alguno ante el ofrecimiento de una máquina agrícola y se retrae de concurrir a los concursos, vid. ROF (1915): «Concursos de ganados en Galicia», La Industria Pecuaria, 1-XII-1915, p. 410.

${ }^{46}$ «La Diputación de Lugo», La Industria Pecuaria, 20-XI-1914, p. 387. Argumentaba la autoridad municipal que se trata de un festejo, y tener prohibido todo gasto que no sea para cosas útiles que fomenten la riqueza de los pueblos y proporcionen trabajo. Contrasta esta actitud con las amargas quejas de la Junta de Coruña ante los problemas de los concursos en Ortigueira, que no podían subsistir con la insignificante ayuda de la AGGR derivando en la discontinuidad de un prometedor proceso de mejora durante la década de los 20, hasta que la Federación Agraria se haga cargo de los mismos Vid. ROSENDE (1988: 176 y ss) y AHN, Fondo Mesta, Leg.780\1.

"CUADERNOS DE ESTUDIOS GALLEGOS", Tomo XLVII, Fascículo 113, Santiago 2000. 
las y favores de cara a conseguir subvenciones y premios para las localidades. Así, el diputado a cortes pontareano Manuel Fernández Barrón movía sus contactos en Madrid en 1922-23 para conseguir concursos en su villa, donde existía una importante tradición en este tipo de eventos ${ }^{47}$. No cabe duda de que es cuando se produce un compromiso manifiesto del poder local y provincial cuando el proceso de difusión de innovaciones experimenta un importante crecimiento, como demuestra el caso de la gestión de De la Sota en la Diputación pontevedresa durante el período primorriverista $^{48}$. Esta interrelación entre poderes locales y difusión de innovaciones traslada al proceso innovador la conflictividad política, muchas veces disfrazada de diferencias de criterios. Por ejemplo el control católico-social de las Diputaciones durante la Dictadura derivó en determinadas coyunturas en el bloqueo de unas actividades vinculadas a «desafectos» laicos como Pita Romero.

«...no puede pues este año la Diputación, aún reconociendo la excepcional importancia de estos concursos, dedicar cifra alguna de su presupuesto al Concurso Nacional de Ganados (...) además cree el Diputado que suscribe que estos servicios como los de los concursos regionales y comarcales pueden ser organizados por la Diputación por medio de sus Consejos Provinciales (...) »"

La conflictividad se extendía al terreno de los técnicos. Con ocasión de los «Concursos Nacionales» fueron frecuentes las disparidades de criterios en torno a los baremos de selección de los ejemplares premiados.

${ }^{47} \mathrm{AHN}$ : Fondo Mesta, Leg. 780 4 . Hay que tener en cuenta la táctica del establecimiento de diferentes fórmulas de difusión de innovaciones como un instrumento más del control del poder local por las elites rurales (POSE \& PERNAS 1997: 388).

${ }^{48}$ En el que, por ejemplo, se consigue la implantación en esta provincia del registro lechero, único en Galicia, junto con las provincias de Madrid, Barcelona, Bilbao, Oviedo, Santander, Sevilla y Murcia, AHN: Fondo Mesta, Leg. 1525. Es en el período primorriverista cuando se consigue también la organización de concursos de carácter «regional» a través del apoyo de Ayuntamientos y Diputaciones.

${ }^{49} \mathrm{El}$ texto procede de un dictamen del Diputado Provincial católico Santos Bugallo, comunicado por la Diputación de A Coruña al Marqués de la Frontera (20-II-1930) en el contexto de las tensiones derivadas por ejemplo del debate suscitado por el ya evidente fracaso del Matadero de Porriño y la caída de la Dictadura,AHN: Fondo Mesta, Leg.876. 
«... que sean revisadas todas las hojas de inscripción de las secciones de ganado vacuno de Raza Gallega, pues en el catálogo no se encuentran los nombres de la mayoría de los ganaderos premiados según la relación expuesta en el pabellón de oficinas de estaAsociación, lo que induce a sospechar que no han sido inscritas» ${ }^{50}$.

El mismo Rof Codina se vió marginado en su participación en los Concursos Nacionales como jurado, hecho relacionable con sus problemas políticos en la recta final de la Dictadura ${ }^{51}$.

Además de los concursos y exposiciones, la AGGR desarrollará en Galicia otra serie de actividades de fomento pecuario como son la participación en la elaboración de la Estadística Pecuaria, los mencionados libros genealógicos del ganado lechero en Pontevedra, la obtención de vacunas contra las epizootias, etc, pero ninguna de ellas con la resonancia y continuidad de las labores de innovación inducida a través de los concursos ganaderos ${ }^{52}$. En todo caso, la vinculación estrecha con los mecanismos clientelares del poder local implicó una distribución desigual de la actividad innovadora así como una serie de dificultades sufridas por determinadas localidades a la hora de incorporarse a esta dinámica ${ }^{53}$.

${ }^{50}$ «Carta de Rof Codina al presidente del jurado del Concurso Nacional (28-V-1922)», AHN: Fondo Mesta, Leg. 1179\2. El mismo Rof solicitaba el cambio del Jurado y del sistema de puntuación pues la Raza Bovina Gallega es la única que tiene un sistema científico propio de apreciación y calificación, que es el único que aceptan y al que se someten los ganaderos que tengo el honor de representar en nombre del Comité Provincial de La Coruña (se refiere Rof al «sistema de mediciones y puntos» desarrollado por él mismo en los Concursos gallegos).

${ }^{51}$ Así se comprueba en su marginación en el jurado del Concurso de 1930, en el contexto de la pugna corporativa dentro de la clase veterinaria entre el grupo de Gordón Ordás y el de Santos Arán, este último más proclive a la AGGR. AHN: Fondo Mesta, Leg. 876.

${ }^{52}$ Incluían estas actividades proyectos de instalación de centros permanentes para la mejora del ganado gallego y difusión de razas selectas, como el proyectado en Lugo a fines de los años 20, vid. AGGR (1929): Memoria presentada por la presidencia de la Asociación General de Ganaderos a la Junta General celebrada el día 25 de abril de 1929, Madrid, p.6.

${ }^{53}$ Así les ocurrió a los vecinos de la entidad local menor de San Martín de Domés (concello de Verea, Ourense) que sufren constantes problemas desde 1926 para obtener ayudas para sus concursos, AHN: Fondo Mesta, Leg. 780\3.

"CUADERNOS DE ESTUdIOS GALLEGOS", Tomo XLVII, Fascículo 113, Santiago 2000. 
El último aspecto a reseñar en la descripción de las actividades de la AGGR en Galicia es la creación de redes adecuadas para la eliminación de los intermediarios en el comercio ganadero con las grandes poblaciones urbanas españolas ${ }^{54}$. En esta línea la AGGR se involucra en los sucesivos intentos de construcción de un entramado cooperativo que regule las exportaciones del sector pecuario gallego colaborando con «católicos» $\mathrm{y}$ «neutros» en dicho empeño. El caso más elocuente de esta ambivalencia es el ortegano, donde la AGGR presta la infraestructura comercial a la FAO y los católicos, en dicha comarca enfrentados por el control del entramado comercial ${ }^{55}$. La AGGR garantizaba al asociacionismo agrario el establecimiento de oficinas receptoras del ganado en los mercados urbanos así como la rápida liquidación de los pagos pertinentes, lo cual no evitaba la rápida contraofensiva de los intermediarios.

«... las que me temo que fracasen son las expediciones de terneras a Barcelona debido a los gastos que ocasionan a los vendedores. Además, los abastecedores de Barcelona proponen a estas Sociedades que les vendan directamente a ellos, obligándose a pagar los precios corrientes en plaza y no cargando gasto alguno desde la llegada de las expediciones a Barcelona. En vista de esta proposición muchos vendedores querían vender el ganado a los abastecedores, a lo que yo me opuse, y después de hacerles toda clase de consideraciones conseguí que siguieran consignando el ganado a la Asociación. Pero la liquidación de esta última expedición ha disgustado a los läbradores y sospecho que mi intervención carecerá de eficacia» ${ }^{56}$.

${ }^{54}$ Se basaba el comercio ganadero en una tupida red de intermediarios establecidos entre el productor y el tablajero, tales eran el tratante, el comisionista y el abastecedor, que promovían un sistema de compra-venta a domicilio o en las feiras -chalaneo- basado en el control sobre la información referente a los precios, vid. AGGR (1921): Memoria presentada a la presidencia de la Asociación General de Ganaderos a las Juntas Generales celebradas en abril de 1931. Una síntesis de los problemas en torno al mercado ganadero en las primeras décadas del siglo XX en BERNÁRDEZ (1998).

${ }^{55}$ En 1919 por ejemplo la Asociación colabora con los PitalMaciñeira y Vázquez Gundín (enfrentados en el poder local ortegano) en la organización de envíos de ganado a Barcelona, AHN: Fondo Mesta, Leg. 1266\2. Precisamente Rosende (1988: 269 y ss) señala como un factor negativo para el desarrollo del comercio ortegano estas pugnas entre las dos corrientes agrarias.

${ }_{56}$ «Carta de Pita Romero al Marqués de la Frontera (10-XI-1919)», AHN: Fondo Mesta, Leg. 1266\2.

"CUADERNOS DE ESTUDIOS GALLEGOS", Tomo XLVII, Fascículo 113, Santiago 2000. 
Estos problemas generaban que la Asociación debiera apoyarse incluso en determinados intermediarios como es el caso del comisionista barcelonés Lorenzo Marí que se encargará del establecimiento de la oficina de laAGGR en Barcelona ${ }^{57}$. Junto con este aspecto, laAsociación intervino como grupo de presión en cuestiones como la política arancelaria y las tarifas ferroviarias, constituyéndose nuevamente en el vocero de facciones diversas del agrarismo aunque en conflicto con frecuencia con alguna de ellas ${ }^{58}$.

\section{CONCLUSIONES}

Hemos intentado presentar en estas páginas una visión general de la presencia de laAsociación General de Ganaderos del Reino, representante de los intereses de los grandes propietarios de la España seca, en una economía agraria de pequeña explotación como es la gallega. En este sentido la Asociación está vinculada con toda una serie de iniciativas que, en la Europa occidental del período 1885-1930, están orientadas a la defensa de la pequeña propiedad como uno de los elementos de la lucha por el mantenimiento de las prerrogativas de la grande. La labor de la AGGR está estrechamente relacionada con los movimientos agraristas de la Galicia del momento en cuanto a fines (consolidación de la pequeña propiedad, cooperativismo), anhelos (defensa arancelaria del sector, eliminación de los intermediarios) e incluso dirigentes (Pita Romero, Rof Codina). Ello debe conducirnos a una reflexión sobre el verdadero carácter de un movimiento social que en las últimas hornadas historiográficas gusta de caracterizarse como alternativo al sistema a pesar de los evidentes puntos comunes con fuerzas sustentadoras del status quo como los católicos o los propios «Ganaderos del Reino».

\footnotetext{
${ }^{57}$ Así se refleja en AHN: Fondo Mesta, Leg. 1266\2, en que se describe el proceso de creación de dicha oficina así como los problemas de Marí con otros intermediarios y con la propia Asociación.

${ }^{58}$ Ya hemos citado las disensiones con los católicos por la cuestión del matadero de Porriño considerando, por ejemplo, los efectos perniciosos que las presiones de los socialcatólicos tenían sobre el mercado madrileño en aspectos como por ejemplo la agremiación forzosa de los carniceros («Libro de Actas de la Comisión Especial de Servicios Cooperativos. Sesión 25-V-1928», AHN: Fondo Mesta, Leg. 1545).
}

"CUADERNOS DE ESTUDIOS GALLEGOS", Tomo XLVII, Fascículo 113, Santiago 2000. 
Mantenemos pues, aún a riesgo de parecer provocadores, que es inevitable considerar a estas fuerzas defensoras del sistema como parte de un movimiento de múltiples colores y que, a fin de cuentas, con frecuencia sirvió de colchón contra fuerzas de proyectos políticos y sociales más definidos en su apuesta por la democracia, el reparto de la riqueza y la autoorganización de las clases subordinadas. Además, el estudio de las organizaciones "patronales» es indispensable para la definición de unas sociedades rurales heterogéneas y con intereses de clase contrapuestos (frente al tópico de la uniformidad de los intereses parroquiales) que se manifiestan en conflictos como el desarrollado en torno al comercio ganadero y que todavía presentan puntos oscuros y tópicos que aclarar.

\section{BIBLIOGRAFÍA}

ALONSO, L.E. (1990): «Agrarismo, populismo y división internacional del trabajo», Agricultura y Sociedad, n55, pp. 65-93.

AMADO MENDES, J.M. (1994): «¿Portugal agrícola o indüstrial? Contornos de una polémica y sus repercusiones en el desarrollo (siglos XIX-XX)», Studia Historica. Historia Contemporánea, vol. 12, pp. 229-258.

ARRIBAS MACHO, J.M. (1989): «El sindicalismo agrario: un instrumento de modernización de la agricultura», Historia Social, $\mathrm{n}^{\circ} 4$, pp. 33-53.

BERNÁRDEZ SOBREIRA, A. (1998): «Os atrancos do sector pecuario galego no contexto da construcción do mercado interior español, 19001921», Documentos de Traballo do Idega, Historia 7, Santiago: Universidade.

CABO VILLAVERDE, M. (1997): «Pensamento económico e agrarismo na primeira metade do século XX», Documentos de traballo do Idega, Historia|3, Santiago: Universidade.

CABO VILLAVERDE, M. (1998): O Agrarismo, Vigo: A Nosa Terra.

"CUADERNOS DE ESTUdIOS GALLEGOS", Tomo XLVII, Fascículo 113, Santiago 2000. 
CABRERA, M. (1983): La patronal ante la II República. Organizaciones y estrategia, 1931-1936, Madrid: S.XXI.

CARDESÍN, J.M. (1992): Tierra, trabajo y reproducción social en una aldea gallega (s.XVIII-XX): muerte de unos, vida de otros, Madrid: MAPA.

CASTILLO, J.J. (1976): Propietarios muy pobres. Sobre la subordinación política del pequeño campesinado, Madrid: MAPA.

CLEARY, M.C. (1989): Politicians and Producers. The Organization of Agriculture in France since 1918, Cambridge: University Press.

DOMÍNGUEZ ALMANSA, A. (1997): A formación da sociedade civil na Galicia rural. Asociacionismo agrario e poder local en Teo, 18901940, Teo: Concello.

DURÁN, J.A. (1977): Agrarismo y movilización campesina en el país gallego (1875-1912), Madrid: S.XXI.

ELORZA, A., ARRANZ, L., REY, F. del, (1986): «Liberalismo y corporativismo en la crisis de la Restauración», in J.L. García Delgado (ed.): La crisis de la Restauración. España entre la I Guerra Mundial y la II República, Madrid: S.XXI, pp. 5-50.

FERNÁNDEZ PRIETO, L. (1992): Labregos con Ciencia. Estado, sociedade e innovación tecnolóxica na agricultura galega, 1850-1939, Vigo: Xerais.

FLORENCIO PUNTAS, A. (1994): Empresariado agrícola y cambio económico (1880-1936), Sevilla: Diputación.

GARCÍA FERRANDO, M. (1977): La innovación tecnológica y su difusión en la agricultura española, Madrid: MAPA.

GARRIDO HERRERO, S. (1994): «Alentar y obstruir. Las vacilaciones de la política estatal sobre cooperativismo en los inicios del siglo $\mathrm{XX}$ », Noticiario de Historia Agraria, no 7, pp. 131-154.

"CUADERNOS DE ESTUDIOS GALLEGOS", Tomo XLVII, Fascículo 113, Santiago 2000. 
GARRIDO HERRERO, S. (1996): Treballar en comú. El cooperativisme agrari a Espanya (1900-1936), Valencia: Eds. Alfons el Magnànim.

HERVÉS SAYAR, E. (1991): «El movimiento agrarista», in AAVV: Historia de Galicia, vol. 4, Vigo: Faro, pp. 857-876.

HERVÉS SAYAR, E. (1997): «O unicato bugallalista: Ponteareas, 18911923. Elementos para unha análise do caciquismo e do clientelismo político na Galicia da Restauración», in L. Fernández et alii (eds.): Poder local, elites e cambio social na Galicia non urbana (1874-1936), Santiago: Universidade, pp. 213-224.

HOBSBAWM, E.J. (1976): Los campesinos y la politica, Barcelona:Anagrama.

HUIZER, G. (1982): «Movimientos de campesinos y campesinas y su reacción ante la depauperación: ¿La dialéctica de la liberación?», Agricultura y Sociedad, n²3, pp. 9-79.

KONING, N. (1994): The Failure of Agrarian Capitalism. Agrarian Politics in the United Kingdom, Germany, the Netherlands and the United States, 1846-1919, Wageningen: Landbouwuniversiteit.

LANGREO NAVARRO, A. (1995): Historia de la industria láctea española. Una aplicación a Asturias, 1830-1995, Madrid: MAPA.

MAJUELO GIL, E. \& PASCUAL BONIS, A. (1991): Del catolicismo agrario al cooperativismo empresarial. Setenta y cinco años de la Federación de Cooperativas Navarras, 1910-1985, Madrid: MAPA.

MARTÍNEZ LÓPEZ, A. (1989): O cooperativismo católico no proceso de modernización da agricultura galega, 1900-1943, Pontevedra: Diputación.

MAYAYO i ARTAL, A. (1995): De pagesos a ciutadans. Cent anys de sindicalisme i cooperativisme agraris a Catalunya, 1893-1994, Barcelona: Afers.

"CUADERNOS DE ESTUDIOS GALLEGOS", Tomo XLVII, Fascículo 113, Santiago 2000. 
MAYER,A. (1984): La persistencia del Antiguo Régimen, Madrid:Alianza.

MILLÁN, J. (1997): «Campesinado y cambio social en la politización de la sociedad contemporánea. Una discusión sobre el conservadurismo agrario valenciano», in L. Fernández et alii (eds.): Poder local, elites e cambio social na Galicia non urbana (1874-1936), Santiago: Universidade, pp. 161-188.

POSE ANTELO, J.M. \& PERNAS OROZA, H. (1997): «O desenvolvemento da política local no marco dun concello rural. A Baña, 19001936», in L. Fernández et alii (eds.): Poder local, elites e cambio social na Galicia non urbana (1874-1936), Santiago: Universidade, pp. 373-392.

PUENTE FERNÁNDEZ, L. de la (1992): Transformaciones agrarias en Cantabria, 1860-1930, Santander: Universidad de Cantabria.

REY REGUILLO, F. del (1992): Propietarios y patronos. La política de las organizaciones económicas en la España de la Restauración (19141923), Madrid: Ministerio de Trabajo.

ROMÁN LAGO, I. (1997): «A heteroxeneidade política como medio de acceso ó poder: As sociedades agrarias de $<<$ vía escocesa $>>$ », in L. Fernández et alii (1997): Poder local, elites e cambio social na Galicia non urbana (1874-1936), Santiago: Universidade, pp. 455-466.

ROSENDE, A.M. (1988): O Agrarismo na comarca do Ortegal (18931936), Sada: Eds. do Castro.

SEVILLA GUZMÁN, E. (1979): La evolución del campesinado en España, Barcelona: Península.

SOUTELO VÁZQUEZ, R. (1996): «Repensando la agencia social de la mesocracia urbana en la relativa modernización de la Galicia rural: Ourense, 1880-1936», Espacio, Tiempo y Forma, serie V, Historia Contemporánea, vol. 9, pp. 85-98.

"CUADERNOS DE ESTUDIOS GALLEGOS", Tomo XLVII, Fascículo 113, Santiago 2000. 
TRACY, M. (1989): Government and Agriculture in Western Europe, 18801988, London: Harvester.

VEIGAALONSO, X.R. (1997): «Desarrollo agrícola y exposiciones: ¿Una relación causal?», Noticiario de Historia Agraria, nº 14, pp. 165-192.

WOLF, E.R. (1971): Los campesinos, Barcelona: Labor. 